\title{
Identification of Rickettsia felis DNA in the blood of domestic cats and dogs in the USA
}

Md Monirul Hoque', Subarna Barua', Patrick John Kelly², Kelly Chenoweth', Bernhard Kaltenboeck and Chengming Wang ${ }^{1 *}$ (D)

\begin{abstract}
Background: The main vector and reservoir host of Rickettsia felis, an emerging human pathogen causing flea-borne spotted fever, is the cat flea Ctenocephalides felis. While cats have not been found to be infected with the organism, significant percentages of dogs from Australia and Africa are infected, indicating that they may be important mammalian reservoirs. The objective of this study was to determine the presence of $R$. felis DNA in the blood of domestic dogs and cats in the USA.

Methods: Three previously validated PCR assays for $R$. felis and DNA sequencing were performed on blood samples obtained from clinically ill domestic cats and dogs from 45 states (2008-2020) in the USA. The blood samples had been submitted for the diagnosis of various tick-borne diseases in dogs and feline infectious peritonitis virus, feline immunodeficiency virus, and Bartonella spp. in cats. Phylogenetic comparisons were performed on the gltA nucleotide sequences obtained in the study and those reported for $R$. felis and $R$. felis-like organisms.

Results: Low copy numbers of $R$. felis DNA (around 100 copies $/ \mathrm{ml}$ whole blood) were found in four cats (4/752, $0.53 \%)$ and three dogs $(3 / 777,0.39 \%)$. The very low levels of infection in clinically ill animals is consistent with $R$. felis being an unlikely cause of disease in naturally infected dogs and cats. The low copy numbers we found emphasize the requirement for very sensitive PCRs in prevalence studies.

Conclusions: The low prevalence of naturally infected PCR-positive cats is further evidence that cats are unlikely to be important reservoirs of $R$. felis. Similarly, the low prevalence in dogs suggests they are not important reservoirs in the USA. Investigations should continue into the role other mammalian species may be playing in the epidemiology of $R$. felis infections.
\end{abstract}

Keywords: Rickettsia felis, Domestic cat, Dog, Whole blood, USA

*Correspondence: wangche@auburn.edu

1 Department of Pathobiology, Auburn University College of Veterinary Medicine, Auburn, AL 36832, USA

Full list of author information is available at the end of the article

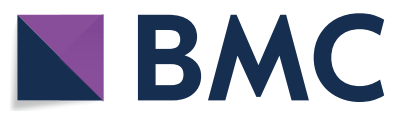

(c) The Author(s) 2020. This article is licensed under a Creative Commons Attribution 4.0 International License, which permits use, sharing, adaptation, distribution and reproduction in any medium or format, as long as you give appropriate credit to the original author(s) and the source, provide a link to the Creative Commons licence, and indicate if changes were made. The images or other third party material in this article are included in the article's Creative Commons licence, unless indicated otherwise in a credit line to the material. If material is not included in the article's Creative Commons licence and your intended use is not permitted by statutory regulation or exceeds the permitted use, you will need to obtain permission directly from the copyright holder. To view a copy of this licence, visit http://creativeco mmons.org/licenses/by/4.0/. The Creative Commons Public Domain Dedication waiver (http://creativecommons.org/publicdomain/ zero/1.0/) applies to the data made available in this article, unless otherwise stated in a credit line to the data. 


\section{Introduction}

The intracellular bacterium Rickettsia felis is the agent of flea-borne spotted fever or cat-flea typhus [1, 2], an emerging zoonotic disease. Since the first report in 1994 of $R$. felis in a person in Texas [3], infections have been described from around the world, with $R$. felis implicated as the causative agent of an important febrile illness in sub-Saharan Africa [4, 5] and flea-borne spotted fever considered a global emerging threat to human health [6].

Various hematophagous arthropods, including a number of flea, tick, and mosquito species, have been found to carry R. felis [6-9], but Ctenocephalides felis felis (cat flea) is the only confirmed biological reservoir and vector of the infectious agent [7]. High percentages of cat fleas from around the world have been found to be infected with $R$. felis - for example, 30-79\% in different U.S. states (Alabama, Maryland, Texas, Oklahoma, and Northern California) [10-12]. Experimental studies have shown that adult $C$. felis felis can become infected by feeding on rickettsemic animals, co-feeding with infected fleas, or as larvae feeding on infected adult feces, eggs, or other larvae $[13,14]$. Infections are passed vertically and transstadially in subsequent generations of fleas, and $R$. felis is found in the salivary glands and be transmitted to mammalian hosts during feeding [15].

A number of mammals have been found to be PCRpositive for $R$. felis DNA, mainly dogs [5], opossums [3, 16], raccoons [17], and rodents [5, 16]. Although cats were originally thought to be the mammalian reservoir hosts, experimental infections only revealed brief asymptomatic rickettsemia 2 months post infection, and then only in five of the 16 cats in the study [18]. Although naturally infected seropositive cats have been identified around the world [13], none have been found to be positive for $R$. felis in PCR assays performed on cats from Australia $(n=11)$ [19], China $(n=135)$ [20], Spain $(n=212)$ [21], Thailand $(n=585)[22,23]$, and the USA $(n=121)[10,12]$. Even cats infested with infected fleas are found to be PCR negative [10, 20, 21]. In the USA, Stephenson et al. reported a Rickettsia seroprevalence of $3 \%$ in people, $42 \%$ in dogs, $79 \%$ in cats, $33 \%$ in gray foxes, and $83 \%$ in bobcats, but reverse transcription (RT)-PCR on blood tested consistently negative [12].

Several studies have shown that apparently healthy dogs are not uncommonly PCR positive for $R$. felis, with $3.5 \%$ of 200 owned dogs testing positive in Zambia [5], 9\% of 100 pound dogs in Australia [1], 2\% of 130 indigenous community semi-domesticated dogs in Australia [2], and a dog in the household of a Spanish flea-borne spotted-fever patient [24]. A recent study has shown experimentally infected dogs can be rickettsemic with $R$. felis for at least 3 months and be infectious for fleas, indicating they are a potential mammalian reservoir of the organism [14].

To shed further light on the R. felis status of dogs and cats from around the USA, we used PCR assays to analyze DNA from clinically ill cats and dogs from 45 states in the USA.

\section{Materials and methods \\ Whole blood samples}

Whole blood samples in EDTA from dogs $(n=777)$ in 45 states of the USA submitted to the Molecular Diagnostics Laboratory at Auburn University College of Veterinary Medicine between 2008 and 2020 for diagnosis of various tick-borne diseases (babesioses, hepatozoonoses, ehrlichioses, and anaplasmoses) were used in the study. We also used whole blood samples in EDTA from domestic cats $(n=752)$ in 43 states submitted for the molecular diagnosis of FIP, FIV, FeLV, and Bartonella infections between 2008 and 2020 . The samples had been sent to Auburn at ambient temperature and, upon arrival, DNA had been extracted from $800-\mu \mathrm{L}$ aliquots using the High-Pure PCR Template Preparation Kit (Roche Molecular Biochemicals, Indianapolis, IN, USA) as previously published [25]. The DNA was eluted in $40 \mu \mathrm{L}$ elution buffer, and the $20-\mu \mathrm{L}$ volume of each sample remaining after the tickborne diseases (dogs) or FIP, FeLV, FIV, and Bartonella (cats) PCR assays had been performed was preserved at $-80^{\circ} \mathrm{C}$ until the PCR assays to detect $R$. felis were performed in this study.

\section{Detection of Rickettsia DNA by PCR}

Three previously validated quantitative PCR assays, mainly a gltA-based Rickettsia FRET-PCR [26], a nestedPCR targeting the gltA of Rickettsia [26], and a R. felis species-specific BioB-based PCR [27], were used to detect Rickettsia DNA in the samples. To optimize the sensitivity of our testing and the relatively small amount of sample DNA available to us, we initially screened 10 $\mu \mathrm{L}$ of each DNA sample with the highly sensitive Rickettsia FRET-qPCR. The remaining DNA of samples positive in the FRET-qPCR was arbitrarily diluted five-fold with $1 \times \mathrm{PBS}$, and $10-\mu \mathrm{L}$ aliquots were used in the nested and $R$. felis species-specific BioB-based PCRs. The $R$. felis DNA from previous studies $[26,28]$ and nucleasefree water were used as positive and negative controls, respectively. The arbitrary fivefold dilution was also performed on the positive controls.

All PCR reactions were performed on a Roche Light Cycler 480 II thermocycler (Roche Diagnostics $\mathrm{GmbH}$, Mannheim, Germany) as previously described [28]. In brief, $10 \mu \mathrm{L}$ of the extracted DNA was added 


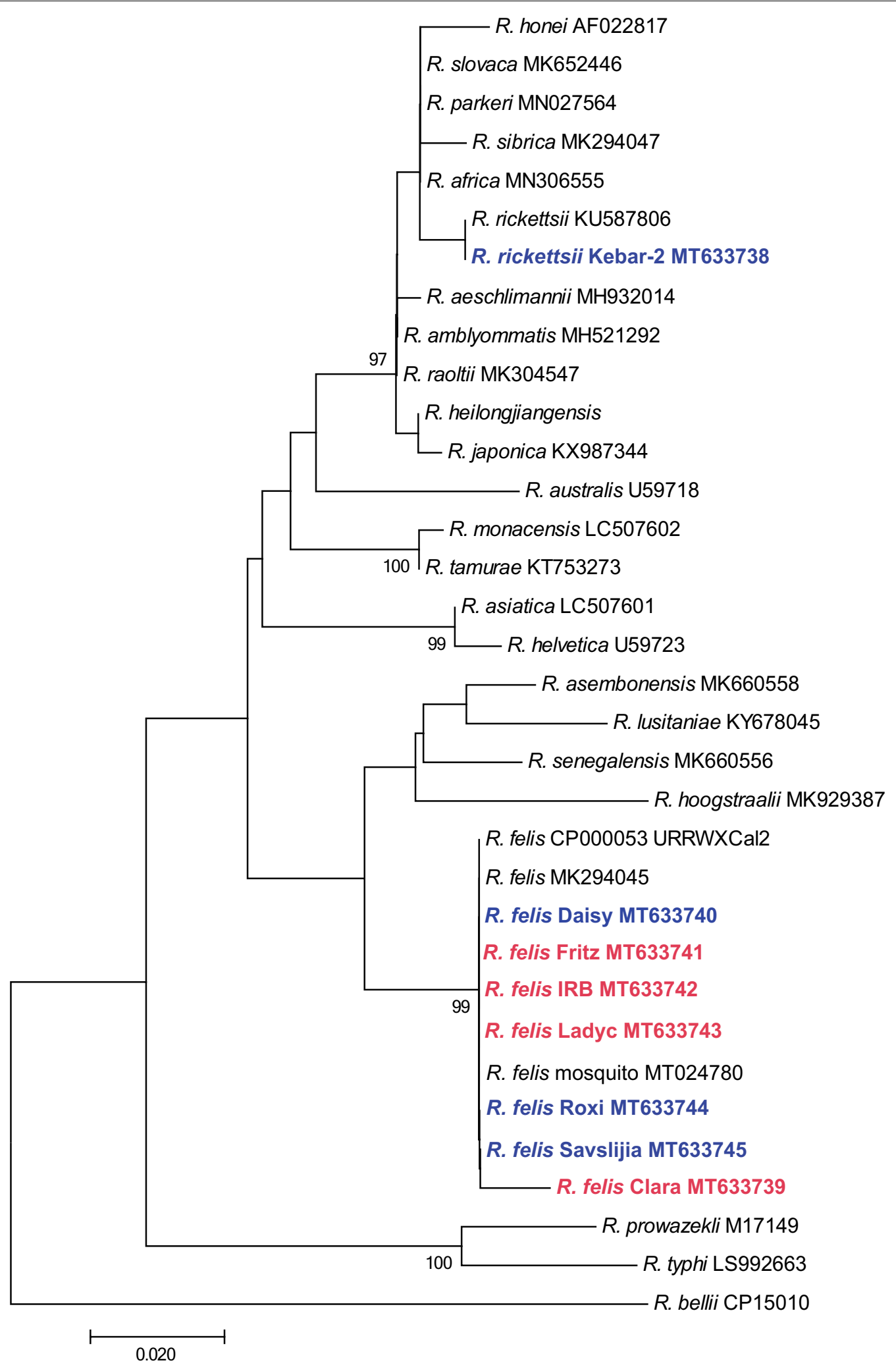

Fig. 1 Phylogenetic tree using a bootstrap analysis for the Rickettsia felis found in mosquitoes from the USA. The names of Rickettsia species and their GenBank Accession numbers are provided. The sequences of $R$. felis identified in this study (in bold; red for cats and blue for dogs) were 99.0-100\% identical to the recognized $R$. felis strains, $94.0 \%$ (R. asembonensis) and $95.7 \%$ (R. senegalensis) identical to $R$. felis-like organisms, and 84.0-94.7\% identical to other Rickettsia spp. 
to a $10-\mu \mathrm{L}$ reaction mixture containing $5 \mathrm{x}$ PCR FRET buffer, $400 \mu \mathrm{M}$ dNTP (Roche Diagnostics GmbH), 0.34 units of Platinum Taq DNA Polymerase (Invitrogen, Carlsbad, CA, USA), $1 \mu \mathrm{M}$ of each forward and reverse primer (Integrated DNA Technologies, Coralville, IA, USA), and a final volume of molecular grade nucleasefree water.

The products of Rickettsia-positive PCRs were sent to ELIM Biopharmaceuticals (Hayward, CA, USA) for Sanger DNA sequencing using upstream and downstream primers. The nucleotide sequences were submitted to the National Center for Biotechnology Information (NCBI) to obtain GenBank Accession numbers, and a phylogenetic tree was generated to compare the nucleotide sequences of Rickettsia identified in this study with those of $R$. felis-like organisms [29] and other Rickettsia species (Fig. 1). The nucleotide sequences of the gltA PCR products were concatenated and aligned using CLUSTALW, and the phylogenetic inferences were obtained from a maximum likelihood analysis.

\section{Results}

The Rickettsia FRET-qPCR identified Rickettsia DNA in nine cats $(1.2 \%)$ and eight dogs (1.0\%). Sequencing confirmed the presence of Rickettsia, but the relatively short amplicon (170 bp) produced by the FRET-qPCR did not enable the reliable differentiation of the species present. Of the 17 FRET-qPCR-positive samples, eight were positive in the nested PCR assays performed with the fivefold diluted DNA (Table 1). Four of these diluted DNA samples were also positive in the R. felis-specific BioB-based PCR assay.

Sequencing of the amplicons of the positive nested PCR assays amplifying the gltA revealed that four cats
(4/752, 0.53\%; standard deviation [SD] 0.073) and three dogs (3/777, 0.39\%; SD 0.062) were positive for $R$. felis and one dog was positive for $R$. rickettsii (Table 1). Six (from 3 dogs and 3 cats) of the seven 300-bp gltA nucleotide sequences were identical to the recognized $R$. felistype strain (CP00053 URRWXCaL2) (Fig. 1) with one, from a cat, having only a single nucleotide difference to the type strain. The sequences of $R$. felis identified in this study had a lower similarity to the $R$. felis-like organisms (94.0\% to R. Asembonensis; $95.7 \%$ to R. senegalensis), and only $84.0-94.7 \%$ similarity to other Rickettsia spp. (Fig. 1).

The R. felis-specific BioB-based PCR assay was positive for all four of the $R$. felis-positive cat samples but was negative for the canine samples (Table 1 ).

The copy number in the FRET-qPCR assay for the $R$. rickettsii-positive dog sample was very high $\left(5 \times 10^{6}\right.$ copies $/ \mathrm{mL}$ whole blood) compared with those for the $R$. felis-positive cats and dogs (about 100 copies/mL whole blood).

The four $R$. felis-positive cats were each from different states: Kansas (sample was submitted in May 2013), California (July 2014), New York (July 2015), and Texas (November 2017). All of the samples were negative by PCR for feline coronavirus and Bartonella spp. for which they had originally been submitted for testing (Table 1).

Three $R$. felis-positive dogs were from Texas (November 2017) and Georgia (December 2014; December 2015), while the $R$. rickettsii-positive dog was from Alabama (June 2013). All of the dog samples had originally been submitted for PCR testing for Hepatozoon spp., and all were negative. Of note: all three $R$. felispositive dogs were suffering from muscle and joint pain (Table 1).

Table 1 Identification of Rickettsia spp. in whole blood of cats and dogs by PCR assay

\begin{tabular}{|c|c|c|c|c|c|c|c|}
\hline Sample ID & Host & State & Year & Background & FRET PCR & Nested PCR & BioB PCR \\
\hline Ladyc & Cat & Manhattan, KS & May 2013 & 5-year; female, spayed; for Bartonella-negative & R. felis & R. felis & R. felis \\
\hline IRBE32218089 & Cat & Granada Hills, CA & July 2014 & 5-year; male castrated; Siamese; for FIP-negative & R. felis & R. felis & R.felis \\
\hline Clara & Cat & Brooklyn, NY & Nov 2015 & $\begin{array}{l}\text { American domestic shorthair; 8-month; female; for FIP- } \\
\text { negative }\end{array}$ & R. felis & R. felis & R. felis \\
\hline Fritz & Cat & Spring, TX & 2017 & $\begin{array}{l}\text { 7-month; American domestic shorthair; male, castrated; for } \\
\text { FIP-negative }\end{array}$ & R. felis & R. felis & R. felis \\
\hline Rebar & Dog & Montgomery, AL & June 2013 & Male; for Hepatozoon-negative & R. rickettsii & R. rickettsii & Failed \\
\hline Daisy & Dog & Killeen, TX & Nov 2017 & $\begin{array}{l}\text { Two-month shifting leg lameness. Jack Russell Terrier Mix; } \\
\text { female, spayed; 6Y. For Hepatozoon-negative }\end{array}$ & R. felis & R. felis & Failed \\
\hline Roxie & Dog & Jefferson, GA & Dec 2014 & $\begin{array}{l}\text { Bulldog; female; 6-year; chronic weight loss with muscle/joint } \\
\text { pain; for Hepatozoon-negative }\end{array}$ & R. felis & R. felis & Failed \\
\hline Kawlija & Dog & Rome, GA & Dec 2015 & $\begin{array}{l}\text { Jack Russell Terrier; 11-year; male; for Hepatozoon-negative; } \\
\text { 6-week history of vomiting/diarrhea; intermittent pain }\end{array}$ & R. felis & R. felis & Failed \\
\hline
\end{tabular}




\section{Discussion}

Rickettsia felis occurs widely around the world, and recent findings that the organism might also be transmitted by mosquitoes [28] have raised the possibility that human flea-borne spotted fever might be the next mosquito-borne pandemic [30]. Expanding our understanding of the mammalian hosts of $R$. felis will be important in developing strategies to prevent and control potential outbreaks.

This study adds to existing data that $R$. felis occurs widely in the USA. To the best of our knowledge, this is the first description of PCR-positive naturally infected domestic cats. However, only very few cats $(4 / 752)$ tested positive, which casts even further doubt on a possible role cats might play as reservoirs of $R$. felis.

Although dogs have commonly been found to be PCR-positive for $R$. felis in Australia [1, 2], we found only low numbers of positive dogs in our study. Previously, we also found only a low percentage $(0.8 \%)$ of dogs $(n=11,059)$ from China to be PCR positive despite $47 \%(128 / 271)$ being seropositive [20], about the same proportion as the $51 \%$ in Australia where 2-9\% of dogs were PCR positive [31]. Similarly, in a study in northern California, Stephenson et al. [12] did not identify $R$. felis DNA in the blood of dogs $(0 / 163)$, although $48 \%$ were seropositive against $R$. rickettsii and $39 \%$ of C. felis $(n=152)$ collected from the dogs were PCR positive. It is of note, however, that it has recently been shown that dogs are reservoirs of $R$. felis, having asymptomatic rickettsemia for up to 100 days after experimental infection and being a source of infection for naïve fleas [14]. The growing body of available data indicates that the importance of dogs in the epidemiology of $R$. felis might vary from area to area. To more precisely determine the role dogs play in the epidemiology of $R$. felis, further studies are needed which consider factors such as dog breed, level of flea infestation, nutritional status, and presence of other vector-borne diseases.

Although, to the best of our knowledge, this is the first description of naturally infected domestic cats that were PCR positive for $R$. felis, actually only very few animals (4/752) were positive, which casts even further doubt on a possible role cats might play as reservoirs of $R$. felis. While the lower level of infections in cats might be because cats are less susceptible to infections, it might also be because cats are only rickettsemic for very short periods before mounting immune responses that clear infections [18]; in contrast, in dogs, circulating $R$. felis may persist for over 3 months [14], which would increase the likelihood of detection in random PCR surveys.
This study is the first to report copy numbers of $R$. felis DNA in dogs and cats. It has previously been suggested that negative results in $R$. felis surveys might have resulted from (1) standard PCR assays having low sensitivity and (2) there being only low circulating levels of the microorganism [10]. The latter possibility appears to be true, as we found only low copy numbers (around 100 copies/mL whole blood) in positive cats and dogs. The FRET-qPCR we developed proved to be very sensitive, detecting one gene copy per $20 \mu \mathrm{L}$ of reaction system [20], and the use of this FRET-qPCR, or at least of equally sensitive PCR assays, appears to be indicated in future studies of mammalian reservoirs of $R$. felis. Although we did not study how copy numbers varied over time, the low copy numbers recorded make it appear likely that dogs and cats can only be efficient reservoirs of infection if there are large populations of fleas and if those fleas are very susceptible to infection.

Our study population consisted of cats and dogs that were clinically ill, with signs suggestive of tick-borne diseases in the dogs and of Bartonella, FIV, or FeLV infections in the cats. The fact that only relatively few of these clinically ill cats and dogs were PCR positive for $R$. felis is consistent with the existing data that infections are typically asymptomatic $[1,2,5,18,31,32]$ and that $R$. felis is an unlikely cause of fever in cats [33].

\section{Conclusion}

In conclusion, this study adds to the body of available data showing that cats are not likely to be important reservoirs of $R$. felis in the USA. Although dogs have been shown to be reservoirs of $R$. felis, the available evidence indicates this might not be the case in the USA. Further studies are needed to identify the factors, such as breed, concurrent disease status, and flea burdens, that would enable dogs to play an important role in the epidemiology of $R$. felis in the USA. Control of human infections must still be directed at the control of fleas on domestic animals as the available evidence indicates these are the major reservoirs and vectors transmitting R. felis. Investigations should continue into the role that other mammalian species may be playing in the epidemiology of $R$. felis infections.

\section{Abbreviations \\ FeLV: Feline leukemia virus; FIP: Feline infectious peritonitis; FIV: Feline immu- nodeficiency virus; FRET: Fluorescence resonance energy transfer.}

\section{Acknowledgements}

We gratefully thank Anwar Kalalah and Anil Poudel for their technical assistance. 


\section{Authors' contributions}

$\mathrm{CW}$ designed the experiment. $\mathrm{MMH}, \mathrm{SB}, \mathrm{KC}$, and $\mathrm{BK}$ obtained the samples and performed the experiment. CW, PJK, and MMH drafted the manuscript. All authors read and approved the manuscript.

\section{Funding}

This research was funded in part by a USDA-ARS program (58-6040-9-017), and by the Alabama Agricultural Experimental Station and the USDA National Institute of Food and Agriculture, Hatch project (ALA052-1-17026).

\section{Availability of data and materials}

Data supporting the conclusions of this article are included within the article

\section{Ethics approval and consent to participate}

The samples used in this study were the remaining samples after diagnostic service. These de-identified samples that would be discarded can be utilized for research without CRRC/IACUC approval.

\section{Consent for publication}

Not applicable

\section{Competing interests}

The authors declare that they have not competing interests.

\section{Author details}

${ }^{1}$ Department of Pathobiology, Auburn University College of Veterinary Medicine, Auburn, AL 36832, USA. ${ }^{2}$ Department of Clinical Sciences, Ross University School of Veterinary Medicine, Island Main Road, West Farm, Basseterre, Saint Kitts and Nevis.

Received: 20 June 2020 Accepted: 5 November 2020

Published online: 18 November 2020

\section{References}

1. Hii SF, Kopp SR, Abdad MY, Thompson MF, O'Leary CA, Rees RL, et al. Molecular evidence supports the role of dogs as potential reservoirs for Rickettsia felis. Vector Borne Zoonotic Dis. 2011;11:1007-12. https://doi. org/10.1089/vbz.2010.0270.

2. Hii S-F, Kopp SR, Thompson MF, O'Leary CA, Rees RL, Traub RJ. Molecular evidence of Rickettsia felis infection in dogs from Northern Territory, Australia. Parasit Vectors. 2011;4(198):39.

3. Schriefer ME, Sacci JB Jr, Taylor JP, Higgins JA, Azad AF. Murine typhus: updated roles of multiple urban components and a second typhus like rickettsia. J Med Entomol. 1994:31:681-5.

4. Parola P. Rickettsia felis: from a rare disease in the USA to a common cause of fever in sub-Saharan Africa. Clin Microbiol Infect. 2011;17:996-1000.

5. Moonga LC, Hayashida K, Nakao R, Lisulo M, Kaneko C, Nakamura I, et al. Molecular detection of Rickettsia felis in dogs, rodents and cat fleas in Zambia. Parasit Vectors. 2019:12(1):1-9. https://doi.org/10.1186/s1307 1-019-3435-6.

6. Angelakis E, Mediannikov O, Parola P, Raoult D. Rickettsia felis: The complex journey of an emergent human pathogen. Trends Parasitol. 2016:32(7):554-64. https://doi.org/10.1016/j.pt.2016.04.009.

7. Higgins JA, Sacci JB, Schriefer ME, Endris RG, Azad AF. Molecular identification of Rickettsia-like microorganisms associated with colonized cat fleas (Ctenocephalides felis). Insect Mol Biol. 1994;3(1):27-33.

8. Parola P, Davoust B, Raoult D. Tick- and flea-borne rickettsial emerging zoonoses. Vet Res. 2005;36(3):469-92. https://doi.org/10.1051/vetre s:2005004.

9. Mediannikov O, Abat C, Sokhna C, Raoult D. Parallel decline of malaria and Rickettsia felis infections in Senegal. Am J Trop Med Hyg. 2018:99(2):360-1.

10. Hawley JR, Shaw SE, Lappin MR. Prevalence of Rickettsia felis DNA in the blood of cats and their fleas in the United States. J Feline Med Surg. 2007;9(3):258-62. https://doi.org/10.1016/j.jfms.2006.12.005.
11. Noden BH, Davidson S, Smith UL, Williams F. First detection of Rickettsia typhi and Rickettsia felis in fleas collected from client-owned companion animals in the Southern Great Plains. J Med Entomol. 2017:54(4):1093-7. https://doi.org/10.1093/jme/tjx069.

12. Stephenson N, Blaney A, Clifford D, Gabriel M, Wengert G, Foley P, et al. Diversity of rickettsiae in a rural community in northern California. Ticks Tick Borne Dis. 2017;8(4):526-31. https://doi.org/10.1016/j.ttbdi s.2017.02.014

13. Reif KE, Macaluso KR. Ecology of Rickettsia felis: a review. J Med Entomol. 2009:46:723-36.

14. Ng-Nguyen D, Hii SF, Hoang MT, Nguyen VT, Rees R, Stenos J et al. Domestic dogs are mammalian reservoirs for the emerging zoonosis fleaborne spotted fever, caused by Rickettsia felis. Sci Rep. 2020;10(1):4151. https://doi.org/10.1038/s41598-020-61122-y.

15. Macaluso KR, Pornwiroon W, Popov VL, Foil LD. Identification of Rickettsia felis in the salivary glands of cat fleas. Vector Borne Zoonotic Dis. 2008;8(3):391-6. https://doi.org/10.1089/vbz.2007.0218.

16. Panti-May JA, Torres-Castro M, Hernández-Betancourt S, Dzul-Rosado K, Zavala-Castro J, López-Avila K, et al. Detection of Rickettsia felis in wild mammals from three municipalities in Yucatan Mexico. EcoHealth. 2015;12:523-7.

17. Sashika M, Abe G, Matsumoto K, Inokuma H. Molecular survey of rickettsial agents in feral raccoons (Procyon lotor) in Hokkaido Japan. Jpn J Infect Dis. 2010;63(5):353-4.

18. Wedincamp J Jr, Foil LD. Infection and seroconversion of cats exposed to cat fleas (Ctenocephalides felis Bouche) infected with Rickettsia felis. J Vector Ecol. 2000;25:123-6.

19. Barrs VR, Beatty JA, Wilson BJ, Evans N, Gowan R, Baral RM, et al. Prevalence of Bartonella species, Rickettsia felis, Haemoplasmas and the Ehrlichia group in the blood of cats and fleas in eastern Australia. Aust Vet J. 2010:88(5):160-5. https://doi.org/10.1111/j.1751-0813.2010.00569.x.

20. Zhang J, Lu G, Kelly P, Zhang Z, Wei L, Yu D, et al. First report of Rickettsia felis in China. BMC Infect Dis. 2014;14:682. https://doi.org/10.1186/s1287 9-014-0682-1.

21. Segura F, Pons I, Miret J, Pla J, Ortuno A, Nogueras M. The role of cats in the eco-epidemiology of spotted fever group diseases. Parasit Vectors. 2014;7:353

22. Assarasakorn S, Veir JK, Hawley JR, Brewer MM, Morris AK, Hill AE, et al. Prevalence of Bartonella species, hemoplasmas, and Rickettsia felis DNA in blood and fleas of cats in Bangkok Thailand. Res Vet Sci. 2012;93(3):12136. https://doi.org/10.1016/j.rvsc.2012.03.015.

23. Phoosangwalthong P, Hii SF, Kamyingkird K, Kengradomkija C, Pinyopanuwata N, Chimnoia W, et al. Cats as potential mammalian reservoirs for Rickettsia sp genotype RF2125 in Bangkok Thailand. Vet Parasitol Reg Stud Rep. 2018;13:188-92. https://doi.org/10.1016/j.vprsr.2018.07.001.

24. Oteo JA, Portillo A, Santibáñez S, Blanco JR, Pérez-Martínez L, Ibarra V. Cluster of cases of human Rickettsia felis infection from Southern Europe (Spain) diagnosed by PCR. J Clin Microbiol. 2006;44(7):2669-71. https:// doi.org/10.1128/JCM.00366-06

25. Li Y, Wang C, Allen KE, Little SE, Ahluwalia SK, Gao D, et al. Diagnosis of canine Hepatozoon spp. infection by quantitative PCR. Vet Parasitol. 2008;157(1-2):50-8

26. Zhang J, Lu G, Li J, Kelly P, Li M, Wang J, et al. Molecular detection of Rickettsia felis and Rickettsia bellii in mosquitoes. Vector Borne Zoonotic Dis. 2019;19:802-9. https://doi.org/10.1089/vbz.2019.2456.

27. Anderson ML, Rustin RC, Eremeeva ME. Pilot survey of mosquitoes (Diptera: (ulicidae) from southeastern Georgia, USA for Wolbachia and Rickettsia felis (Rickettsiales: Rickettsiaceae). J Vector Borne Dis. 2019;56:92-7. https://doi.org/10.4103/0972-9062.263714.

28. Barua S, Hoque MM, Kelly PJ, et al. First report of Rickettsia felis in mosquitoes, USA. Emerg Microbes Infect. 2020;9(1):1008-10. https://doi. org/10.1080/22221751.2020.1760736.

29. Odhiambo AM, Maina AN, Taylor ML, Jiang J, Richards AL. Development and validation of a quantitative real-time polymerase chain reaction assay specific for the detection of Rickettsia felis and not Rickettsia felis-like organisms. Vector Borne Zoonotic Dis. 2014;14(7):476-81. 
30. Parola P, Musso D, Raoult D. Rickettsia felis: the next mosquito-borne outbreak? Lancet Infect Dis. 2016;16(10):1112-3. https://doi.org/10.1016/ S1473-3099(16)30331-0.

31. Hii SF, Abdad MY, Kopp SR, Stenos J, Rees RL, Traub RJ. Seroprevalence and risk factors for Rickettsia felis exposure in dogs from Southeast Queensland and the Northern Territory Australia. Parasit Vectors. 2013:6:159. https://doi.org/10.1186/1756-3305-6-159.

32. Wedincamp J Jr, Foil LD. Vertical transmission of Rickettsia felis in the cat flea (Ctenocephalides felis Bouché). J Vector Ecol. 2002:27(1):96-101.
33. Bayliss DB, Morris AK, Horta MC, Labruna MB, Radecki SV, Hawley JR, et al. Prevalence of Rickettsia species antibodies and Rickettsia species DNA in the blood of cats with and without fever. J Feline Med Surg. 2009;11:266-70.

\section{Publisher's Note}

Springer Nature remains neutral with regard to jurisdictional claims in published maps and institutional affiliations.
Ready to submit your research? Choose BMC and benefit from:

- fast, convenient online submission

- thorough peer review by experienced researchers in your field

- rapid publication on acceptance

- support for research data, including large and complex data types

- gold Open Access which fosters wider collaboration and increased citations

- maximum visibility for your research: over $100 \mathrm{M}$ website views per year

At BMC, research is always in progress.

Learn more biomedcentral.com/submissions 